\title{
Allowing the best of each person to emerge: A reflection on student-academic partnership in developing two multimedia tools for peer-assisted learning in medical education
}

\author{
*Leon Le Blanc, School of Medicine, Royal College of Surgeons in Ireland (RCSI), Ireland. \\ Mathew Kelly, School of Medicine, University College Dublin (UCD), Ireland. \\ Mary Higgins, University College Dublin Perinatal Research Centre, National Maternity \\ Hospital, University College Dublin (UCD), Ireland.
}

Contact: leonleblanc@RCSI.com

Medical students have undoubtedly experienced their fair share of challenges in continuing their studies during the COVID-19 pandemic. Opportunities to undertake a leadership role in creating multimedia tools, which form the basis of blended learning in today's universities, are key to maintain and support students in navigating their medical degree. Such opportunities have become scarcely available over the COVID-19 pandemic. It is important for medical students to take on such leadership roles as hospitals are incredibly team-focussed and require team leaders with vision, discipline, knowledge, and empathy.

At the core of the partnership work discussed in this essay is the question of how medical students can better find a balance to learn the empathy needed to talk with patients while also being able to highlight key medical knowledge during a consultation. The process of reflection outlined below showed the difficulties in capturing that balance. The exploration of this difficulty is the contribution of this work to the literature. From the medical students' perspective in this project, when there was a focus on conveying empathy to the patient, there were instances where subpar medical advice was provided. Conversely, when the focus was placed on conveying quality medical information to the patient, the manner of speaking often lacked empathy and warmth.

In the unprecedented summer of 2020 for students and academic staff alike, a partnership was formed between a group of nine medical students and one professor of obstetrics and gynaecology. The group worked collaboratively online over a concentrated 3-week period on a medical education project. This student-generated project was entirely virtual due to COVID-19 restrictions in Ireland. Of the nine students, eight attended University College Dublin (UCD) and one attended The Royal College of Surgeons (RCSI) in Ireland. The eight UCD students had just completed the fourth year of their medical degree, with the sole RCSI student completing their third year. Three of the nine students were studying medicine as their postgraduate degree, with the remainder completing their medical undergraduate degree. The professor had many years of teaching experience in obstetrics and gynecology and was affiliated with UCD and the National Maternity Hospital in Ireland. 
Together, the nine students designed and developed two multimedia tools as part of an elective module in their medical degree. The students were given free rein over the development and distribution of both tools. The collaborative practice-based work was based in the National Maternity Hospital in Dublin, Ireland. The professor recruited the students through the UCD and RCSI email network. All nine students contributed to both of the multimedia tools, with two students selected to act as project leads. The project leads assigned specific jobs to each student and acted as the main point of contact with the professor.

The first multimedia tool is a 200-question multiple-choice question (MCQ) bank to support formative assessment. The aim was for students to gain a greater understanding of the subject matter by being responsible for researching and writing the MCQs in their entirety. In their study, Kelly et al. (2018) found that student-developed MCQs can enhance the value of MCQs as a form of assessment. This parallels what we ourselves experienced insofar as there was generally a positive impact on those of our subsequent assessments which were based on MCQs. These original MCQs were written collectively by the nine students and reviewed by the professor of obstetrics and gynecology. The second technology tool was a podcast on a range of key topics in the same fields of study as the MCQs. The original podcast scripts and the MCQ bank were both written by the students following The Royal College of Obstetricians and Gynecologists guidelines (RCOG) ${ }^{1}$. Both the podcasts and the MCQs were distributed to fourth-year medical students undertaking their rotation in obstetrics and gynaecology. The reflections in this paper were developed by the team and written after the completion of the elective. The implications for short, focused student partnerships in learning and teaching in medical education domains in higher education will be discussed.

\section{STUDENT AND STAFF REFLECTIONS}

All reflections are considered under the themes of:

- the challenges of reaching depth in medical content knowledge,

- group dynamics,

- the power relationship in the student-staff partnership, and

- grappling with new technologies.

\section{Depth of medical content knowledge}

The podcast scripts were written using the RCOG guidelines to provide accurate and factual information. In addition to this, we also used knowledge we had acquired over the years of our programme. However, when we proofread the scripts, we noticed the language came across as detached and impersonal. We found it incredibly challenging to write the podcast scripts in a way that would ensure a sense of empathy and compassion was shown towards the patient, while also including appropriate, quality medical content. By the time we had included all the necessary medical knowledge in a coherent and factual way, we discovered there was little room left for empathetic language. We noticed it was easier for us to write the scripts to contain all the medical knowledge required to conduct a wellinformed consultation with a patient. We felt this is because medical knowledge and information can be learned from a book, something all nine of us had become accustomed to throughout our years studying medicine. Educational interventions may play a role in enhancing empathy in undergraduate students, as commented on by Batt-Rawden et al. (2013). However, we feel empathy is something that is developed in a person over time as 
they talk to and examine patients, maturing and honing their communication skills. Speaking to patients is an area of our work that we as students have not had as much exposure to, yet a basic principle of medicine is to have no other teacher than the patient. Empathy and compassion are much more than language and words; it depends on how you say it to the patient. As such, the tone of voice used when recording the podcasts was very important. In clinical life, body language and facial expressions are also crucial to convey empathy. The way a doctor speaks to a patient is just as important as what they say. This concept can sometimes be overlooked in clinical practice, which is why it was so crucial for us to make sure we got it right.

It was a great help to be able to submit the scripts to the professor and for her to edit them where appropriate. Initially, the professor did think about the consequences of the students lacking the clinical experience to ensure the scripts had an element of empathy when dealing with sensitive subject matters (e.g., ectopic pregnancy, miscarriage):

I did have some initial misgivings, but I reviewed the scripts to ensure the content and language was appropriate. The tone of voice is also important and I think they got this right. They are such a great bunch of people that their natural empathy comes through.

In addition to the podcast scripts, we found our content knowledge lacking when we began the development of the 200-question MCQ bank. One of the cornerstones of medical assessments is the MCQ assessment. Since our first year of college, we have completed numerous of these exams every year. As a result, we felt as though we would have no problem developing a question bank of our own. However, it soon became clear to us that developing these type of questions was not as straight-forward as it seemed initially. We found that the change in the power dynamic from the staff-led development of these questions to a student-focused process caused us to doubt ourselves. Normally it is the academic staff who write the questions for our exams. For this reason, we as students tended to view these questions as infallible. They have been designed by individuals with years of experience in their chosen medical field. How can we call their knowledge into question when we ourselves have spent so little time studying the subject matter? When the time arose for us to develop the questions, we found the experience very disconcerting. As such, all of us felt vulnerable to criticism. For every question that we wrote, we would relentlessly scrutinize it in an attempt to ensure all the information was correct. None of us wanted to appear as novices in front of our peers by writing questions that contained inaccurate information.

Another layer of anxiety stemmed from the fact that we were worried that on seeing our questions, the professor would have to spend time correcting them. Each of us wanted to show that we could pull our weight on this project and not channel the professor's time into amending our mistakes, which would have left us feeling self-conscious. We invested a significant amount of our own time into clearly and explicitly writing each question, which resulted in it being an arduous process.

\section{Group dynamics}

Draper and Fisher (2020) highlighted that students will often retain practices of education learned from schooling in their pre-university years. We all had been involved in projects before but only ever acted under the direct supervision of the academic staff who 
led the project. We were not used to the idea of being in co-control of the design and development process. As such, we often became reliant on utilizing research strategies learned in our pre-university education or first few years of university study. Only through writing this reflective piece did we realize that we have still not fully acclimatized to university education and group work.

Looking back, how we interacted together as a group could have posed a problem with regards to how we interacted and exchanged ideas. The fact that there were students from two different universities (the RCSI student also being in third year and the rest in fourth year) meant the group dynamics could have easily become a challenge to navigate. This can be seen in the reflections of the sole RCSI student who said,

Knowing I would be developing the multimedia tools with students from another university that I didn't know, and who were in a year above on the programme, was somewhat intimidating. Previously I never had any exposure working with students from different years or different universities, and I was concerned that I would not be able to keep up with the older students based on my assumption that they have had more experience working on group-based projects. While reading up around group dynamics, I came across a reflection by Pelnar et al. (2020) which detailed how she (as the youngest member of the team) experienced imposter syndrome. This resonated with me and aligned with how I felt in the early days of the project. Before starting, I was afraid I wouldn't fit in with the older students and would feel as though my work and suggestions were not the same standard as theirs.

Going into this project, the professor also had some concerns regarding students from two different universities working together on the project. Reflecting on how the project went, her concerns were allayed:

I was worried that because the two different universities ran very different courses (RCSI is more reliant on simulation than UCD and uses a goal-based assessment) that there would not be commonality; that and that there was only one RCSI student that he may be overwhelmed by the group-but he assimilated very well, and I think this really contributed to the group to have two different viewpoints.

It was decided at the beginning of the project that two group leaders would be appointed by the students to act as a direct channel of correspondence with the professor. This could have been a source of conflict among the students, who potentially could have felt disgruntled at the prospect of having to answer to one of their peers. Thankfully, the two group leaders took their role seriously and delegated tasks to those who they considered would be best able to complete them. In this regard, we felt as though having students acting as leaders on the project was superior to having academic staff. In previous projects, members of staff would assign roles at random to students. Since we all worked closely together, there was a mutual understanding of each other's strengths and weaknesses. This allowed the group leaders to delegate tasks to those who they felt best had the skills to overcome the challenging part. If one of us appeared to be struggling with a section of work, the group leaders would recognise this and assign one of the other students who they felt had a sufficient knowledge base to draw upon. This allowed us to make the best use of everyone's skills. As reflected upon by one student, group leaders aimed to not 
only ensure the skillset of every person in the group was used appropriately but also "to avoid a scenario where one person did all the work on the MCQs while another spent all their time on the podcasts."

Distinct benefits and barriers to a student partnership project were identified by two of us:

We all have differing strengths, and this project, more than any other I have been involved in, allowed the best of each person to emerge. For example, if I had done this project alone, aside from taking much longer, it would have been far less detailed, stylish, and functional.

However, it was important for everyone to remain cognisant of the potential barriers and conflicts that could have arisen when engaging in this work:

There is always an undercurrent of tension in the early stages of a project where $2+$ members of a team have differing ideas. Without a project leader these tend to go unresolved but as we had one for both MCQs and podcasts, any potential conflict was addressed before it had a chance to grow. In addition to the project leaders, we also had the professor. After discussing ideas amongst ourselves, if we were unsure of anything or felt as though there was conflict arising, we were able to approach the professor for input and guidance, which we all found very helpful. As such, I don't think I saw any real conflicts. The only barrier was the 3-week timeframe.

As an educator, the professor was aware of the difficulty of writing good quality MCQs, and going into the project, she equally harboured no concerns about the students' ability to self-manage the process of writing and amassing an MCQ bank. However, she was wary of the potential for students to experience burnout during the process. As a result, she was eager for the students to elect group leaders:

I had no doubts about their ability, but I did have concerns that they may find it painful and wish to give up. I was cognisant that writing a 200-question MCQ bank and developing a podcast series all by themselves may be too much to take on. Assigning two group leaders who would act as correspondents with me and who would distribute out tasks among everyone was a good idea so no one person was overwhelmed.

Glover et al. (2020) discussed the importance of students building inter-professional relationships in order to feel like a cohesive team. Similarly, we wanted to reach a stage where it didn't feel like it was UCD and RCSI students working independently but rather a collective of university students united towards a common goal. The third-year student reflected,

As I was the sole RCSI student in the project, I was very aware of the need to integrate with the UCD students for the success of the project. This reflects the hospital setting where interdisciplinary teams and meetings has become the gold standard for patient care. I didn't want to let myself or my university down. I knew I 
needed to rely on my peers to help me work through the project, but I wanted to show to them that I was capable of pulling my own weight.

Everyone on the team had significant commitments outside of the elective. The students were busy studying for upcoming exams and preparing for the next year of college. The professor of obstetrics was working in the National Maternity Hospital in Dublin during a global pandemic. With the benefit of hindsight, it is a testament to our collective commitment that we were able to carve out time to meet virtually three times a week to discuss our progress and the direction of the project.

We found that over the duration of the project we learned valuable lessons from our peers. Specifically, the third year RCSI student found this to be so:

I appreciated the opportunity to work alongside the fourth-year students. I admired their work ethic and dedication to the project. I saw first-hand how they effectively communicated with each other and the professor via the group leaders. We as students now feel that what we have learnt can be applied to other work, and we were all in agreement that we will have more faith in group work in years to come.

\section{Student and staff partnership}

From the students' perspective, we were exploring entirely new territory because, never having acted as co-leads on a project before, we had no idea initially how to cope with the workload. There was a feeling amongst the students that we had something to prove to our professor and each other. As discussed in Martens et al. (2019), in order to render student and staff partnerships more effective, students should be empowered further. This is a point we all strongly agreed with. We wanted to show that even though we were students, there was more than enough collective capability amongst us to take on these two multimedia tools and succeed in their production.

Throughout the project, the professor delivered lectures and led tutorials on both medical education and learning theories. Her aim from the tutorials and lectures was for us to identify a problem faced by students across both universities during the course of study and to design a project to address that issue. It was to be a project developed for students by students. The tutorials were there to guide us in identifying approaches to develop learning tools that could aid in our study of medicine. Our thoughts on the learning theory tutorials were captured by one student:

To be involved in a practical project that resulted in so much output was very rewarding. I also learned a lot about delivering education which I greatly appreciated. Going in, I had no idea that we would be learning so much about education theory, but I feel as though it served to help us all understand what kind of approach we should take when developing the MCQ bank and podcast. It wasn't just about throwing some stuff together to get through this elective but rather about taking the necessary steps to try and develop these multimedia tools in a way that would maximise our understanding and future students' ability to learn.

Armed with knowledge on learning theory from the professor, the group leaders were better able to identify areas of the development process that could be made more efficient. It was through these professor-led tutorials on learning theory that the idea emerged to 
design both a podcast series and MCQ bank, and as part of our pre-reading, we were encouraged to research around the topic. We came across several interesting papers that we felt could guide us in deciding on how to spend the 3 weeks of the project and focus on what to develop. As Pashler et al. (2009) noted, different students learn better through certain mediums (e.g. listening, reading, writing), and we felt that in order to maximise the reach of our project amongst the students and staff of both universities, it would be important to include two tools that cover two different learning styles. Students can listen to podcasts, or they may practice written MCQs, depending on how they feel they study best.

\section{New technologies}

One aspect none of us had considered would be the difficulty in traversing this new digital landscape in a post COVID-19 world. Any projects we had been involved with before had taken place in person on university campus or in a hospital. The development of the MCQ bank and podcast series took place entirely over Zoom and via email correspondence. This posed new challenges for us, especially when it came time to review and edit other students' work. We felt it was daunting initially to critique each other's work via Zoom. Through the pandemic we have all experienced, at one time or another, difficulties in perceiving body language and a poor internet connection. These can play a negative role in how criticism is perceived.

However, technology can also be a useful medium for alleviating project-related stress. The professor held an "icebreaker" via Zoom to try and help us become more comfortable talking to each other. We all found it helpful to get us talking to each other from the start. Getting to know the other students gave us all the confidence to speak up with suggestions and a critique about each other's work, a vital part of any effective teambased project. Lerchenfeldt et al. (2020) noted that critiquing peers' work is a vital part of a collaborative-based project, something we all strongly agree with.

The nature of the multimedia design and development project was also unfamiliar to us all. Before this project, none of us had ever written online MCQs or developed a podcast. This helped put us all on a level playing field when it came to knowing the technology that we needed to use and deciding on the best approach for developing the two multimedia tools. As a result, we were expecting to gain some technological skills from using the tools as well as enhancing our content knowledge, as highlighted by one student:

Honestly, I was hoping for some clinical experience given the lack of it available lately. It was a nice surprise that we got so much from this project. I hadn't looked over any Obs and Gynae notes for a while, so it was great to refresh the information I had studied in the past and to learn so much more throughout the process. I had absolutely no experience with writing MCQs or making a podcast from scratch, so it was nice to broaden my skills by doing both as part of the project.

Despite our lack of previous exposure to MCQ and podcast design, the professor did not foresee any difficulty arising regarding our technological ability to develop a multimedia tool and had "full confidence in [us] as digital natives." 


\section{CONCLUSION}

As students, we found this project had a positive impact in broadening our understanding of the difficulties associated with developing high-quality MCQs. Writing the podcast scripts showed us the importance of patient contact in developing empathy in an individual. Our goal with the podcast series was to allow the listener to see the interaction from either the doctor or the patient's perspective. It is important for us as medical students to be able to relay information to a patient, but it is equally important that we are able to put ourselves into the patient's shoes to appreciate how the information will be perceived.

Some of us favoured a direct approach when writing the scripts and would keep the information concise and centred on medical knowledge. Others tried to have the script focus more on the doctor-patient interaction, with an emphasis placed on using empathetic language rather than medical jargon. In the end, we were able to collaborate so that each script contains elements of both approaches as we felt this provided a more rounded podcast.

We greatly appreciated the involvement of our professor in providing advice and taking the time to teach core education concepts throughout the project. Without the professor's input, the quality of the multimedia tools would not have been as high.

From the professor's perspective, having student involvement in the project resulted in some fresh thinking emerging. The students came up with ideas that otherwise may not have been thought of. In terms of the technology required to store and distribute an MCQ bank and podcast series, the students were very adept at traversing the technological landscape to make such an ambitious project possible. The MCQ bank has been distributed to fourth-year students from both universities and the podcast has been posted publicly. Positive feedback from students in both universities can be evidenced by requests to expand the number of episodes in the podcast series. As of February 2021, there have been an additional six episodes added to the podcast series, with plans to add more episodes in the future ${ }^{2}$.

\section{NOTES}

\section{1. https://www.rcog.org.uk/guidelines}

2. To listen to our podcast (Obscast: UCD Student Podcast), visit: https://open.spotify.com/show/6BK8k6Cvq2mUL4Lv1b0Csb?si=25r gwtsQH2FwSeQytwV7A \&nd $=1$

\section{NOTE ON CONTRIBUTORS}

Leon Le Blanc is a third-year undergraduate student studying medicine in the Royal College of Surgeons in Ireland (RCSI).

Mathew Kelly is a fourth year post graduate student studying medicine in University College Dublin (UCD). 
Mary Higgins is an Associate Professor in UCD, and a consultant (attending) in Obstetrics and Gynaecology in the National Maternity Hospital with a subspeciality in Maternal Foetal Medicine. She is an Associate Fellow AMEE and a Fellow of the Academy of Medical Educators, RCPI and RCOG.

\section{REFERENCES}

Batt-Rawden, S. A., Chisolm, M. S., Blair, A., Flickinger, T. E. (2013). Teaching empathy to medical students. An updated, systematic review. Academic Medicine, 88(8), 11711177. https://doi.org/10.1097/ACM.0b013e318299f3e3

Draper, M. J. \& Fisher, D. (2020). A student and staff partnership in the development of a student-directed independent learning toolkit. International Journal for Students as Partners, 4(2). https://doi.org/10.15173/ijsap.v4i2.4086

Glover, N., Knox, K. J., Kirman, B., Topham, M., Westbury-Hawkins, K., \& Holland, P. (2020). Catastrophic co-production: A student-staff partnership for developing an educational game. International Journal for Students as Partners, 4(2). https://doi.org/10.15173/ijsap.v4i2.4120

Kelly, M., Ryan, A., Henderson, M., Hegerty, H., \& Delany, C. (2018). Students designing assessment for future practice. MedEdPublish, 7(2). https://doi.org/10.15694/mep.2018.0000121.1

Lerchenfeldt, S., \& Taylor, T. (2020). Best Practices in peer assessment: Training tomorrow's physicians to obtain and provide quality feedback. Advances in Medical Education and Practice, 11, 571-578. https://doi.org/10.2147/AMEP.S250761

Martens, S. E., Spruijt, A., Wolfhagen, I., Whittingham, J., \& Dolmans, D. (2019). A students' take on student-staff partnerships: Experiences and preferences. Assessment \& Evaluation in Higher Education, 44(6), 910-919. https://doi.org/10.1080/02602938.2018.1546374

Pashler, H., McDaniel, M., Rohrer, D., \& Bjork, R. (2009). Learning styles: Concepts and evidence. Psychological Science in the Public Interest: A Journal of the American Psychological Society, 9(3). https://doi.org/10.1111/j.1539-6053.2009.01038.x

Pelnar, H., Reyes, G., Sehgal, K., \& Cameron, L. (2020). Partners, not peers: Defining boundaries and expectations in student partnerships. International Journal for Students as Partners, 4(2). https://doi.org/10.15173/ijsap.v4i2.4289 